\title{
Impact of physical factors on activities of honey bees: potential hazards and future perspectives
}

\author{
Hossam F. Abou-Shaara* \\ Department of Plant Protection, Faculty of Agriculture, Damanhour University, Damanhour, 22516, Egypt \\ ${ }^{\star}$ Corresponding author, E-mail: hossam.farag@agr.dmu.edu.eg
}

\begin{abstract}
Different physical factors (electric and electromagnetic fields, magnetic field, gravity, and light) can negatively affect activities of honey bee (Apis mellifera L.) either inside or outside the hives, possibly causing damage to bee colonies. In this paper, previous studies are reviewed to shed more light on the effects of these factors on honey bees, and to provide suggestions for additional investigations. Comb building, waggle dance, flight, and navigation have gained more attention than other activities. Also, worker bees have been studied more than drones and queens, and especially adults more than immature stages. Productivity aspects of bee colonies and biological parameters have not been the focus of most studies. Effects of the reviewed physical factors on bee-parasite interactions have gained little attention. The possibility of considering these physical factors as a serious hazard to honey bees is discussed. It seems that the field of honey bee physics is open for future investigations with focus on bee-parasite and bee-environment interactions.
\end{abstract}

Key words: Aplis mellifera, colonies, electric field, electromagnetic field, honey bee biology, light, receptors.

Abbreviations: e-field, electric field; EMF, electromagnetic field; CCD, colony collapse disorder; MF, magnetic field; RF-EMF, radiofrequency electromagnetic fields.

\section{Introduction}

Electric and electromagnetic fields, magnetic field, gravity, and light can affect honey bee Apis mellifera L. (Hussaini et al. 2009; Ferrari 2014; Hepworth et al. 2015; Abou-Shaara, Elbanoby 2018; Shepherd et al. 2018), especially since that honey bees have many activities both inside and outside their hives (Abou-Shaara 2014). These physical factors are connected to each other. In brief, electricity is related to the motion of electric charge while electrically charged objects have both an electric field (e-field) and electromagnetic field (EMF), due to their magnetic properties.

Light is electromagnetic radiation, which is affected by gravity like other energy forms. In this paper, available literature regarding these factors is reviewed in view of their potential effects on honey bees. This review has special importance because these physical factors, especially electromagnetic radiation, have gained much concern during the last few years due to their potential link in combination with other factors to the sudden disappearance of bee colonies, which is commonly known as colony collapse disorder (CCD; e.g. Oldroyd 2007; Maini et al. 2010; Neumann, Carreck 2010; Pattazhy 2012). This article also highlights gaps in knowledge and presents suggestions for future investigations.

\section{Electric and electromagnetic fields}

\section{Exposure to electric and electromagnetic fields}

When present on a conductive substrate and exposed to an e-field, bees indicate disturbance, showing alteration in their behavior, including sting, while on an insulator bees show only vibrations of body parts without behavioral alterations (Bindokas et al. 1989). Also, bees caged in PVCcages show higher electric body loading and activity than in grounded steel cages (Altmann, Warnke 1979). It is possible to produce pure venom from bee colonies using electric shock (Benton et al. 1963), and by using fans with electrical controlled units for adjustment of microclimate inside colonies (Abou-Shaara et al. 2013). It is expected that the material of hives or various supplied devices can have specific e-field or EMF that can affect honey bees. Thus, this aspect needs further investigations.

Bee colonies exposed to a $765 \mathrm{kV}$ electric field showed abnormal activities, queen loss, production of queen cells, and weak winter survival, but at 7 and $5.5 \mathrm{kV} \mathrm{m}^{-1}$ foraging activity was affected passively (Greenberg et al. 1981). Bee colonies exposed to high voltage e-fields $(50 \mathrm{~Hz})$ can have abnormally altered thermography during winter (Altmann, Warnke 1987). Bees exposed to $60 \mathrm{~Hz}$ showed vibrations of wings, antennae, and body hairs (Bindokas et al. 1989), and colonies exposed to electromagnetic radiation from 
digital enhanced cordless telephones showed less returning ability than untreated bees (Kimmel et al. 2007). Also, worker piping, as an indicator of swarming or colony disturbance, has been induced when colonies were exposed to electromagnetic waves from mobile phones (Favre 2011). These studies show the possible negative effects of e-fields on honey bees under certain conditions.

\section{Receptors and generators}

Honey bees have the ability to detect weak electric fields using mechanoreceptors (sensors) in both joints of the antennae (Greggers et al. 2013), especially at short distances (less than $10 \mathrm{~cm}$; reviewed in Clarke et al. 2017). The body integuments have a role in the generation of electric fields due to their properties to carry large electrostatic charge (Es'kov et al. 1976). Thus, electric fields are emitted by bees during their activities (i.e. flying, walking and waggle dance; Greggers et al. 2013). Surface electric potentials of bee workers have a daily rhythm and are partially affected by weather conditions. Bees entering and leaving the hive are positively charged while those leaving the hive early in the day are slightly negatively charged (Erickson 1975), and cluster bees during winter have higher charges than forager bees (Colin et al. 2009). Basically, temperature and relative humidity can greatly affect in- and out-colony activities of honey bees (Abou-Shaara et al. 2017). It is considered that fluctuations in bee e-fields are associated with temperature and relative humidity.

\section{Bee-parasite interactions}

External parasites (mainly Varroa mites) require specific cues to reach to the host bees including chemical cues, and electric charges can also play a role. Although this aspect can be rarely studied it has been shown that Varroa mites are attracted to metallic cylinder charged with intensities similar to that of living bees in cases of negative charge (Colin et al. 1992). This reflects the possible role of e-fields to be used by Varroa mites to locate its host.

\section{Bee-environment interactions}

Exposure to radio-frequency electromagnetic field (RFEMF) can cause harmful impacts on living organisms, including bees (Sivani, Sudarsanam 2012). Ecological effects of RF-EMF are not limited to high dosages, but also low dosages (Cucurachi et al. 2013). Gary and Westerdahl (1981) found no adverse effects on flight, orientation, and memory of foraging bees exposed to $2.45 \mathrm{GHz}$ continuous wave microwaves. However, bees exposed to $50 \mathrm{~Hz}$ extremely low frequency electromagnetic field (ELF EMF) at levels from $20-100$ to $1000-7000 \mu \mathrm{T}$ showed reduced learning ability with abnormal flight dynamics, accompanied by lower ability to locate food sources (Shepherd et al. 2018). More studies are needed to identify the threshold distance between location of bee hives and sources of EMF to protect bee colonies from any negative impacts.
Pollination occurs when bee workers exhibit foraging behavior in order to collect food resources. The ability of honey bees to possess electric charges may have role in pollen transfer during pollination (Erickson 1982; Erickson, Buchmann 1983). Pollen can be electrostatically bound on bee surfaces (Corbet et al. 1982). Pollen transfer is promoted by the accumulated charge on a bee (GanMor et al. 1995). The role of e-fields during pollination and competition between honey bees and other pollinators requires further study.

\section{Biological effects}

Under certain defined laboratory conditions some biological impacts of EMF on honey bees were found. Exposing bee drones to cell phone radiation causes an increase in carbohydrate, protein and lipid concentrations of semen with decreasing seminal enzyme ectivity (Kumar 2012). Also, increase in concentration of some biochemicals (carbohydrates, proteins and lipids of haemolymph) has been reported for honey bee drones exposed to electromagnetic radiations from cell phones (Kumar et al. 2013). Moreover, exposure of bee larvae to high RFEMF causes reduction in catalase activity and the lipid peroxidation level, and damages DNA (Vilić et al. 2017). More investigations on these biological effects are required, particularly considering other bee castes.

\section{Magnetic field}

There are some observable behaviors related to geomagnetic field, including comb building (De Jong 1982), orientation to hives (Lindauer, Martin 1968), and foraging activity (Walker, Bitterman 1985; Walker et al. 1989; Lambinet et al. 2014).

\section{Magnetoreceptors}

Honey bees have the ability to identify geomagnetic fields by magnetoreception (Kirschvink 1981; Kirschvink, Kobayashi 1991; Lambinet et al. 2017a), and have magnetite particles in the abdomen (Walker, Bitterman 1989), with size about $30 \mathrm{~nm}$ (Desoil et al. 2005), which respond to magnetic field stimuli. Normal bees are able to associate the magnetic stimulus with a sucrose reward, while bees without neural connection between the abdomen and the thorax are not (Liang et al. 2016). A recent study by Lambinet et al. (2017b) provided support on the role of magnetite-based magnetoreceptors in abdomens of honey bees. Moreover, hairs on the abdomen of honey bees are considered as an upper-paramagnetic magnetite (Schiff, Canal 1993), and paramagnetism occurs only in the abdomen of adult workers and queens (Takagi 1995).

Magnetoreception in many species depends on the existence of tiny crystals of $\mathrm{Fe}_{3} \mathrm{O}_{4}$ (Kirschvink et al. 2001). Different iron structures (e.g. $\mathrm{Fe}^{3+}$ and $\mathrm{FeOOH}$ ) have been identified in honey bees (El-Jaick et al. 2001). Magnetic nanoparticles are presented in antennae, head, thorax 
and abdomen of young and adult workers (Chambarelli et al. 2008). The iron granules in the trophocytes are randomly distributed in workers and drones while they are clustered in queens (Hsu, Li 1993), suggesting a role in magnetoreception (Hsu, Li 1994; Hsu et al. 2007). It is clear that magnetoreceptors in honey bees have not been sufficiently studied.

\section{Activities of honey bees}

Few studies have focused on the effects of magnetic field on honey bees. It is known that the mating of bee queens occurs in the air (Gary 1963) with many drones (e.g. Taber, Wendel 1985; Neumann, Moritz 2000) at drone congregation areas (Zmarlicki, Morse 1963). A magnetic field (MF) may affect the formation of drone congregation areas (Loper 1992), and can reduce the flying activity of honey bees with increase of life span by more than $60 \%$ and decreased brain lipofuscin (ageing pigment) (Martin et al. 1989). Exposing honey bees to fluctuations in magnetic fields and the earth's magnetosphere can impair the ability of bees to return to their hives (Ferrari 2014), and a MF of 3.75 Oe can affect the mobility of bee workers (Hepworth et al. 2015). Additionally, some biochemical changes (decrease of trehalase enzyme activity and increase of phospholipid concentration in workers) can occur under strong magnetic fields (Kefuss et al. 1999). It is apparent that the effects of MF on productivity aspects of bee colonies have not been the focus of previous studies.

\section{Gravity}

Gravity is basically different from magnetism. Gravity acts between any two objects with mass (e.g. earth and bees) while magnetism depends on properties of objects (e.g. presence of iron granules). Honey bees have specific receptors, cushions of sensory hairs, between the head, thorax, and abdomen and on all the leg joints of bees for sensing gravity (Tautz 2008). Gravity can serve as a reference line instead of the sun during some activities of honey bees inside hives, including dance language and comb building (Tautz 2008). Additionally, gravity has role in orientation of larvae inside wax cells, which is very important for survival and especially for queens (Jay 1963). Recently, protein fibers of royal jelly were found to play a role in preventing queen larvae falling out of their cells especially when cell is vertically oriented and opening downwards (Buttstedt et al. 2018). Unfortunately, potential effects of gravity in link with other physical factors on activities of bee colonies have not been well studied.

\section{Light}

\section{Sun compass}

Flight activity of honey bees changes seasonally in association with light intensity and temperature (Nelson, Jay 1967). Flight activity occur mostly from early morning until evening (Abou-Shaara 2014). Honey bees are able to update their memories regarding information on the Sun's course or new landmarks (Dyer 1987), and under laboratory conditions are able to identify the Sun's course using innate internal representation (Dyer, Dickinson 1994). Moreover, honey bees can learn the relationship between the sun's pattern of movement and a newly-experienced landscape (Towne 2008; Kemfort, Towne 2013), and bees depend on their memory to locate the location of the sun under overclouded skies in new landscapes (Dovey et al. 2013).

Light and gravity can impact the waggles angle and direction to a food source (Edrich 1977, Leucht 1984). Blue and yellow-green lights have a role in dance directions and is considered as sunlight (Edrich et al. 1979) while polarized UV light affects orientation of honey bees to gravity (Edrich 1979). Additionally, the amount of solar UV-B light has no passive influence on foraging activity (Collins et al. 1997).

Night activity has been reported in honey bees (Robinson and Morse 1982), and honey bees can see at night (Warrant et al. 1996). Also, bees infected with the parasitic phorid (Apocephalus borealis) can flight at night and are attracted to artificial light sources (Core et al.2012). It is evident that the Sun compass is necessary for honey bees, while nocturnal activities are very limited.

\section{Effects of light}

Concerning comb building, exposing clustered bees to bright light by day hinders the start of comb building, while it starts within a few hours or days in the dark, and can continue in the dark or in daylight (Morse 1965). Regarding sleep rhythm, honey bees sleep more during the dark than the light phase (Hussaini et al. 2009), and each of young and forager bees exhibit sleep behavior but with different rhythms (Eban-Rothschild, Bloch 2008). Also, sleep rhythm changes with bee age and tasks (Klein et al. 2008). When forage is not available, foragers tend to nap during the day (Klein, Seeley 2011). Brood rearing is affected by temperature and is modulated by photoperiod (Nürnberger et al. 2018).

Bees deprived from sleep show an ability of sleep intensification to compensate sleep deficit (Sauer et al. 2004). Abnormal waggle dance leading to imprecise communication can occur in case of sleep deprivation (Klein et al. 2010). Moreover, olfactory learning can be influenced by light condition (Lehmann et al. 2011). Honey bee drones kept in complete darkness survive slightly longer than those exposed to 12/12 h dark/light (Abou-Shaara, Elbanoby 2018). Understanding of the effects of light in combination with other biological and physical factors on honey bees and colony activities requires additional investigations.

\section{Critical analysis}

Under laboratory conditions, e-fields and EMFs have a few negative impacts on honey bees (Kumar 2012; Kumar et al. 
2013; Vilić et al. 2017). Experiments have shown negative effects on foraging, clustering and other activities of honey bees under different levels of e-fields and EMFs (Greenberg et al. 1981; Altmann, Warnke 1987; Kimmel et al. 2007; Favre 2011; Shepherd et al.2018), but there are contrasting studies (Gary and Westerdahl 1981; Carreck 2014). The results of previous studies greatly vary according to experimental conditions, but in general support the potential hazards of EMF on honey bees. Honey bees under field conditions are affected by many factors, including temperature, relative humidity, exposure to pesticides, and other factors. Identification of the specific impacts of e-field and EMF without overlapping with the other factors need designed experiments. The effects of harsh temperature,either high or low, on honey bees (Abou-Shaara et al. 2017) are expected to be higher than the effects of e-fields and EMFs, but additional studies on these physical factors are still needed.

Apart from the natural effects of magnetic field, gravity, and light on honey bees, very few studies have investigated the effects of the artificial exposure to these factors on honey bees under field and laboratory conditions. The passive impacts of a magnetic field on honey bees has been demonstrated (Kefuss et al. 1999; Ferrari 2014; Hepworth et al.2015), but the reported impacts can not be considered as a hazard to honey bees. Gravity and light have been studied in relation to the dance language of honey bees, and mostly utilizing the natural gravity and light levels, without exposing the bees to artificial sources. Light effects have been more studied than gravity, especially in regard to sleep rhythm and waggle dance (Sauer et al. 2004; Klein et al. 2010). The natural levels of magnetic fields, gravity, and light may vary with location and altitude, and wide comparisons between apiaries at different geographical locations are needed to better understand the impacts of these factors.

\section{Conclusion and outlooks}

Previous studies, in general, support the presence of negative effects of the reviewed physical factors at specific levels on honey bees, but more studies are needed to consider these factors as a serious hazard to honey bees. It seems that many aspects related to e-fields, MFs, EMFs, gravity and light are not completely understood and the methods of study have not been standardized. The effects of the reviewed factors on honey bees are variable in relation to treatment, exposure method and experimental conditions. Adult bee workers have gained more attention than other stages or reproductive castes of honey bees. Perhaps the role of electric charges as cues during pollination, communication, and other activities is not as high as other types of stimuli (e.g. chemical cues). However, this role may be essential when the role of the other cues is rather low or absent. Concerning e-fields and EMFs, little is known about interactions between hive and frame materials (plastic, wooden, etc.) and electric properties of honey bees. The role of e-fields during bee clustering, swarming, queen rearing, and absconding has not been highlighted. More insights are required on the role of e-fields and EMFs on bee-Varroa interactions, without neglecting the role of hive material. Additionally, the effect of pesticides on alteration of the e-field of bees needs to be studied together with their ability to affect bee-plant interactions. More investigations are required on magnetic field effects in the formation of drone congregation areas and flight activity of drones and queens. The effect of gravity on the development of honey bees as well as impact of light on nocturnal activities and survival of honey bees need further studies.

These following aspects of the reviewed physical factors need further investigation: (i) effects on immature stages and reproductive castes of honey bees, (ii) variations between honey bee subspecies, (iii) effects on productivity and performance of honey bee colonies over seasons, (iv) impacts on physiological and biological characteristics of honey bees, (v) interaction with apiary location on activities of colonies, (vi) effects during queen rearing and replacement, bee swarming and absconding, (vii) potential effects on bee pests and diseases, (viii) correlation with bee health and nutritional level, (ix) interactions with environmental factors including temperature and relative humidity, and $(\mathrm{x})$ interaction with environmental pollution.

\section{References}

Abou-Shaara H.F. 2014. The foraging behaviour of honey bees, Apis mellifera: a review. Vet. Med. 59: 1-10.

Abou-Shaara H.F., Al-Ghamdi A.A., Mohamed A.A. 2013. Honey bee colonies performance enhance by newly modified beehives. J. Apic. Sci. 57: 45-57.

Abou-Shaara H.F., Elbanoby M.I. 2018. Factors impacting survival of mature honey bee drones kept in small laboratory cages. Environ. Exp. Biol. 16: 455--463.

Abou-Shaara H.F., Owayss A.A., Ibrahim Y.Y., Basuny N.K.. 2017. A review of impacts of temperature and relative humidity on various activities of honey bees. Insect Soc. 64: 455-463.

Altmann G., Warnke U. 1987. Thermographie der honigbienen wintertraube unter einflußvon hochspannungswechselfeldern. J. Appl. Entomol. 104: 69-73.

Altmann G., Warnke U. 1979. Effects of electric environmental factors on the behaviour of encaged honey bees. Anzeiger fuer Schaedlingskunde Pflanzenschutz Umweltschutz 52: 17-19.

Benton A.W., Morse R.A., Stewart J.D. 1963. Venom collection from honey bees. Science 142: 228-230.

Bindokas V.P., Gauger J.R., Greenberg B. 1989. Laboratory investigations of the electrical characteristics of honey bees and their exposure to intense electric fields. Bioelectromagnetics 10: 1-12.

Buttstedt A., Mureşan C.I., Lilie H., Hause G., Ihling C.H., Schulze S.-H., Pietzsch M., Moritz R.F.A. 2018. How honeybees defy gravity with royal jelly to raise queens. Curr. Biol. 28: 10951100.

Carreck N. 2014. Electromagnetic radiation and bees, again. Bee World 91: 101-102. 
Chambarelli L.L., Pinho M.A., Abraçado L.G., Esquivel D.M.S., Wajnberg E. 2008. Temporal and preparation effects in the magnetic nanoparticles of Apis mellifera body parts. J. Magn. Magn. Mater. 320: e207-e210.

Clarke D., Morley E., Robert D. 2017. The bee, the flower, and the electric field: electric ecology and aerial electroreception. J. Comp. Physiol. A 203: 737-748.

Colin M.E., Richard D., Chauzy S. 2009. Measurement of electric charges carried by bees: Evidence of biological variations. J. Bioelect. 10: 17-32.

Colin M.E., Richard D., Fourcassie V., Belzunces L.P. 1992. Attraction of Varroa jacobsoni, parasite of Apis mellifera by electrical charges. J. Insect Physiol. 38: 111-117.

Collins S.A., Conner J.K., Robinson G.E. 1997. Foraging behavior of honey bees (Hymenoptera: Apidae) on Brassica nigra and B. rapa grown under simulated ambient and enhanced UV-B radiation. Ann. Entomol. Soc. Am. 90:102-106.

Corbet S.A., Beament J., Eisikowitch D. 1982. Are electrostatic forces involved in pollen transfer? Plant Cell. Environ. 5: 125129.

Core A., Runckel C., Ivers J., Quock C., Siapno T., DeNault S., Brown B., DeRisi J., Smith C.D., Hafernik J., Raine N.E. 2012.A new threat to honey bees, the parasitic phorid fly Apocephalus borealis. PLoS One 7: e29639.

Cucurachi S., Tamis W.L.M., Vijver M.G., Peijnenburg W.J.G.M., Bolte J.F.B., De Snoo G.R. 2013. A review of the ecological effects of radiofrequency electromagnetic fields (RF-EMF). Environ. Int. 51: 116-140.

De Jong D. 1982. Orientation of comb building by honeybees. J. Comp. Physiol. 147: 495-501

Desoil M., Gillis P., Gossuin Y., Pankhurst Q.A., Hautot D. 2005. Definitive identification of magnetite nanoparticles in the abdomen of the honeybee Apis mellifera. J. Phys. Confer. Ser. 17: 45 .

Dovey K.M., Kemfort J.R., Towne W.F. 2013. The depth of the honeybee's backup sun-compass systems. J. Exp. Biol. 216: 2129-2139.

Dyer F.C, Dickinson J.A. 1994. Development of sun compensation by honeybees: How partially experienced bees estimate the sun's course. Proc. Natl. Acad. Sci. USA 91: 4471-4474.

Dyer F.C. 1987. Memory and sun compensation by honey bees. J. Comp. Physiol. A 160: 621-633.

Eban-Rothschild A.D., Bloch G. 2008. Differences in the sleep architecture of forager and young honeybees (Apis mellifera). J. Exp. Biol. 211: 2408-2416.

Edrich W. 1977. Interaction of light and gravity in the orientation of the waggle dance of honey bees. Anim. Behav. 25: 342-363.

Edrich W. 1979. Honey bees: Photoreceptors participating in orientation behaviour to light and gravity. J. Comp. Physiol. 133: 111-116.

Edrich W., Neumeyer C., von Heiversen O. 1979. "Anti-sun orientation" of bees with regard to a field of ultraviolet light. J. Comp. Physiol. 134: 151-157.

El-Jaick L.J., Acosta-Avalos D., de Souza Esquivel D.M., Wajnberg E., Linhares M.P. 2001. Electron paramagnetic resonance study of honeybee Apis mellifera abdomens. Eur. Biophys J. 29: 579-586.

Erickson E.H. 1975. Surface electric potentials on worker honeybees leaving and entering the hive. J. Apic. Res. 14: 141147.

Erickson E.H. 1982. Evidence of electrostatic enhancement of odor receptor function by worker honeybee antennae.
Bioelectromagnetics 3: 413-420.

Erickson E.H., Buchmann S.L. 1983. Electrostatics and pollination. In: Jones C.E. (ed) Handbook of Experimental Pollination Biology. Van Nostrand Reinhold, New York, pp. 173-184.

Es'kov E.K., Sapozhnikov A.M. 1976. Mechanism of generation and perception of electric fields by honey bees. Biofizika 21 : 1097-1102.

Favre,D. 2011. Mobile phone-induced honeybee worker piping. Apidologie 42: 270-279.

Ferrari T.E. 2014. Magnets, magnetic field fluctuations and geomagnetic disturbances impair the homing ability of honey bees (Apis mellifera). J. Apic. Res. 53: 452-465.

Gan-Mor S., Schwartz Y., Bechar A., Eisikowitch D., Manor G. 1995. Relevance of electrostatic forces in natural and artificial pollination. Can. Agr. Eng. 37: 189-194.

Gary N.E, Westerdahl B.B. 1981. Flight, orientation, and homing abilities of honeybees following exposure to $2.45 \mathrm{GHz} \mathrm{CW}$ microwaves. Bioelectromagnetics 2: 71-75.

Gary N.E. 1963. Observations of mating behaviour in the honeybee. J. Apic. Res. 2: 3-13.

Greenberg B., Bindokas V.P., Gauger J.R. 1981. Biological effects of a $765-\mathrm{kV}$ transmission line: Exposures and thresholds in honeybee colonies. Bioelectromagnetics 2: 315-328.

Greggers U., Koch G., Schmidt V., Dürr A., Floriou-Servou A., Piepenbrock D., Göpfert M.C., Menzel R. 2013. Reception and learning of electric fields in bees. Proc. Biol. Sci. 280: 20130528.

Hepworth D., Pickard R.S., Overshott K.J. 2015. Effects of the periodically intermittent application of a constant magnetic field on the mobility in darkness of worker honeybees. J. Apic. Res. 19: 179-186.

Hsu C.Y., Li C.W. 1993. The ultrastructure and formation of iron granules in the honeybee (Apis mellifera). J. Exp. Biol. 180: $1-13$.

Hsu C.Y., Ko F.Y., Li C.W., Fann K., Lue J.T. 2007. Magnetoreception system in honeybees (Apis mellifera). PloS One 2: e395.

Hsu C.Y., Li C.W. 1994. Magnetoreception in honeybees. Science 265: 95-97.

Hussaini S.A., Bogusch L., Landgraf T., Menzel R. 2009. Sleep deprivation affects extinction but not acquisition memory in honeybees. Learn. Mem. 16: 698-705.

Jay S.C. 1963. The longitudinal orientation of larval honey bees (Apis mellifera) in their cells. Can. J. Zool. 41: 717-723.

Kefuss J., M’Diaye K., Bounias M., Vanpoucke J., Ecochard J. 1999. Biochemical effects of high intensity constant magnetic fields on worker honey bees. Bioelectromagnetics 20: 117-122.

Kemfort J.R., Towne W.F. 2013. Honeybees can learn the relationship between the solar ephemeris and a newly experienced landscape: a confirmation. J. Exp. Biol. 216: 37673771.

Kimmel S., Kuhn J., Harst W., Stever H. 2007. Electromagnetic radiation: influences on honeybees (Apis mellifera). Preprint IIAS-InterSymp Conference, Baden-Baden. http://agbi. unilandau.de/material_download/preprint_IAAS_2007.pdf.

Kirschvink J.L. 1981. The horizontal mganetic dance of the honeybee is compatible with a single-domain ferromagnetic magnetoreceptor. Biosystems 14: 193-203.

Kirschvink J.L., Kobayashi A. 1991. Is geomagnetic sensitivity real? Replication of the Walker-Bitterman magnetic conditioning experiment in honey bees. Am. Zool. 31: 169-185.

Kirschvink J.L., Walker M.M., Diebel C.E. 2001. Magnetite-based magnetoreception. Curr. Opin. Neurobiol. 11: 462-467.

Klein B.A., Klein A., Wray M.K., Mueller U.G., Seeley T.D. 2010. 
Sleep deprivation impairs precision of waggle dance signaling in honey bees. Proc. Natl. Acad. Sci. USA 107: 22705-22709.

Klein B.A., Olzsowy K.M., Klein A., Saunders K.M., Seeley T.D. 2008. Caste-dependent sleep of worker honey bees. J. Exp. Biol. 211: 3028-3040.

Klein B.A., Seeley T.D. 2011. Work or sleep? Honeybee foragers opportunistically nap during the day when forage is not available. Anim. Behav. 82: 77-83.

Kumar N.R. 2012. Influence of cell phone radiations on Apis mellifera semen. J. Global Biosci. 1: 17-19.

Kumar N.R., Neha R., Preeti K. 2013. Biochemical changes in haemolymph of Apis mellifera L. drone under the influence of cell phone radiations. J. Appl. Nat. Sci. 5: 139-141.

Lambinet V., Hayden M.E., Bieri M., Gries G. 2014. Does the Earth's magnetic field serve as a reference for alignment of the honeybee Waggle dance? PloS One 9: e115665.

Lambinet V., Hayden M.E., Reid C., Gries G. 2017a. Honey bees possess a polarity-sensitive magnetoreceptor. J. Comp. Physiol. A 203: 1029-1036.

Lambinet V., Hayden M.E., Reigl K., Gomis S., Gries G. 2017b. Linking magnetite in the abdomen of honey bees to a magnetoreceptive function. Proc. Biol. Sci. 284: 20162873.

Lehmann M., Gustav D., Galizia C.G. 2011. The early bee catches the flower-circadian rhythmicity influences learning performance in honey bees, Apis mellifera. Behav. Ecol. Sociobiol. 65: 205-215.

Leucht T. 1984. Responses to light under varying magnetic conditions in the honeybee, Apis mellifica. J. Comp. Physiol. A 154: 865-870.

Liang C.H., Chuang C.L., Jiang J.A., Yang E.C. 2016. Magnetic sensing through the abdomen of the honey bee. Sci. Rep. 6: 23657.

Lindauer M., Martin H. 1968. Earths magnetic field affects orientation of honeybees in gravity field. Zeitschr. Vergleich. Physiol. 60: 219.

Loper G.M. 1992. Evidence of magnetic influence on the formation of honey bee (Apis mellifera L.) drone congregation areas. Bee Sci. 2: 71-76.

Maini S., Medrzycki P., Porrini C. 2010. The puzzle of honey bee losses: a brief review. Bull. Insectol. 63: 153-160.

Martin H., Korall H., Förster B. 1989. Magnetic field effects on activity and ageing in honeybees. J. Comp. Physiol. A 164: 423431.

Morse R.A. 1965. The effect of light on comb construction by honeybees. J. Apic. Res. 4: 23-29.

Nelson E.V., Jay S.C. 1967. Flight activity of honeybees in a flight and rearing room. I. The influence of light intensity. J. Apic. Res. 6: 179-183.

Neumann P., Moritz R.F.A. 2000. Testing genetic variance hypotheses for the evolution of polyandry in the honeybee
(Apis mellifera L.). Insect Soc. 47: 271-279.

Nürnberger F., Härtel S., Steffan-Dewenter I. 2018. The influence of temperature and photoperiod on the timing of brood onset in hibernating honey bee colonies. Peer J. 6: e4801.

Oldroyd B.P. 2007. What's killing American honey bees?. PLoS Biol. 5: e168.

Pattazhy S. 2012. Electromagnetic radiation (EMR) clashes with honey bees. J. Entomol. Nematol. 4: 1-3.

Robinson G.E., Morse R.A. 1982. Number of honey bees that stay out all night. Bee World 63: 173-174.

Sauer S., Herrmann E., Kaiser W. 2004. Sleep deprivation in honey bees. J. Sleep Res. 13:145-152.

Schiff H., Canal G. 1993. The magnetic and electric fields induced by superparamagnetic magnetite in honeybees. Biol. Cybern. 69: 7-17.

Shepherd S., Lima M.A.P., Oliveira E.E., Sharkh S.M., Jackson C.W., Newland P.L. 2018. Extremely low frequency electromagnetic fields impair the cognitive and motor abilities of honey bees. Sci. Rep. 8: 7932.

Sivani S., Sudarsanam D. 2012. Impacts of radio-frequency electromagnetic field (RF-EMF) from cell phone towers and wireless devices on biosystem and ecosystem - a review. Biol. Medic. 4: 202-216.

Taber III S., Wendel J. 1985. Concerning the number of times queen bees mate. J. Econ. Entomol. 51: 786-789.

Takagi S. 1995. Paramagnetism of honeybees. J. Phys. Soc. Jpn. 64: 4378-4381.

Tautz J. 2008. The Buzz About Bees: Biology of a Superorganism. Springer Verlag, Berlin-Heidelberg.

Towne W.F. 2008. Honeybees can learn the relationship between the solar ephemeris and a newly-experienced landscape. J. Exp. Biol. 211: 3737-3743.

Vilić M., Tlak Gajger I., Tucak P., Štambuk A., Šrut M., Klobučar G., Malarić K., Žura Žaja I., Pavelić A., Manger M., Tkalec M. 2017. Effects of short-term exposure to mobile phone radiofrequency $(900 \mathrm{MHz})$ on the oxidative response and genotoxicity in honey bee larvae. J. Apic. Res. 56: 430-438.

Walker M.M., Baird D.L., Bitterman M.E. 1989. Failure of stationary but not of flying honeybees (Apis mellifera) to respond to magnetic field stimuli. J. Comp. Psychol. 103: 62-69.

Walker M.M., Bitterman M.E. 1985. Conditioned responding to magnetic fields by honeybees. J. Comp. Physiol. A 157: 67-71.

Walker M.M., Bitterman M.E. 1989. Conditioning analysis of magnetoreception in honeybees. Bioelectromagnetics 10: 261275.

Warrant E., Porombka T., Kirchner W.H. 1996. Neural image enhancement allows honeybees to see at night. Proc. Royal Soc. B 263: 1521-1526.

Zmarlicki C., Morse R.A. 1963. Drone congregation areas. J. Apic. Res. 2: 64-66. 